\title{
How effective are tobacco industry bar and club marketing efforts in reaching young adults?
}

\author{
E A Gilpin, V M White, J P Pierce
}

Tobacco Control 2005;14:186-192. doi: 10.1136/tc.2004.009712

See end of article for authors' affiliations

\section{Correspondence to:} John P Pierce, PhD, Cancer Prevention and Control Program, Rebecca and John Moores UCSD

Cancer Center, University of California, San Diego, La Jolla, California, 92093-0645, USA; ippierce@ucsd.edu

Received 19 October 2004 Accepted 10 January 2005
Objective: Recently, the tobacco industry has focused marketing efforts on young adults through bar and club promotions, such as advertising and distribution of free cigarettes in these settings. This study estimates the fraction of the California young adult population that might be exposed and potentially influenced by these efforts.

Design and participants: Data were from 9364 young adult (18-29 years) respondents to the cross sectional population based 2002 California Tobacco Survey. As background, we analysed social smoking (only smoke with other smokers), and enjoyment of smoking while drinking. Our main focus was on bar and club attendance, what was observed in bars and clubs, and how this might differ according to respondents' risk for future smoking.

Results: Social smokers comprised $30.0(2.2) \%$ of all current smokers, including experimenters. Nearly three quarters (74.5 (2.3)\%) of current smokers/experimenters said they enjoyed smoking while drinking. About one third (33.8 (1.2)\%) of all young adults said they attended bars and clubs at least sometimes; attendance was significantly higher among smokers and those at risk for future smoking. Close to $60 \%$ (57.9 (2.2)\%) of bar and club attenders reported seeing cigarette advertising and promotions in these settings. Again, smokers and those at risk were more likely to report seeing such advertising and promotions in these settings.

Conclusions: About $20 \%$ of all young adults and about $30 \%$ of those at risk for future smoking (including current smokers) were exposed to tobacco advertising and promotions in bars and clubs. These California results may be conservative, but nonetheless indicate that the group potentially influenced is sizable. $\mathrm{b}$ n 1998, provisions of the Master Settlement Agreement between leading tobacco companies and US state attorneys general restricted marketing practices demonstrated to appeal to children and adolescents. ${ }^{1-6}$ This development led the tobacco industry to focus more on young adults. There is considerable evidence in tobacco industry documents of extensive research to identify optimal strategies to influence this group. ${ }^{7}$ However, there is little information about the exposure of the general young adult population to such strategies, and the present study addresses this issue.

The industry documented that because of the many transitions that occur during young adulthood (for example, leaving home, entering college, the military, or the workforce), people are more open to trying new things and that social environments are important places where this might occur. ${ }^{78}$ Joining in accepted social activities is part of what young adults do for fun. By making smoking a normal and integral part of the bar and club scene, the tobacco industry can use this important young adult social environment to its advantage to promote smoking. The industry is apparently using other young adult social environments, such as college social events (for example, sorority and fraternity parties) to this purpose as well, and attendance at such events was associated with higher smoking rates in a recent study. ${ }^{9}$

Bar and club patrons are supposedly of legal age to drink (21 years), and promotional activities are allowed in "adults only" venues. ${ }^{10}$ As a measure of the growth of the industry's marketing efforts in bars and clubs, advertisements in the alternative press (popular among young adults) for cigarettes, bar or club promotions and special tobacco company sponsored events increased steadily from only a few to many hundreds a year between 1995 and 1999. ${ }^{11}$

Promoting smoking in bars and clubs has further advantages. Drinking might reduce a never smoker's inhibitions about trying a cigarette, a former smoker's resolve to remain a non-smoker, or a social smoker's intent to smoke only a cigarette or two in an evening. ${ }^{12}$ Drinking and smoking are activities that often occur together among young people. ${ }^{13-16}$ Also, research suggests that people perceive an added effect from smoking if they consume alcohol at the same time. ${ }^{16}$ Finally, a recent animal study suggests that the pairing of alcohol and nicotine dramatically increases nicotine dependence during the adolescent and early adult period but not during the mature adult phases of the life cycle. ${ }^{17}$

Given that the tobacco industry is using bars and clubs as venues to promote smoking, it is important to determine what fraction of the young adult population (18-29 years) is exposed and thereby possibly influenced by these marketing efforts. In this article, we use data from the large population based 2002 California Tobacco Survey (CTS) to identify the extent and characteristics of young adult smokers who patronise bars and clubs, and we tabulate what they report seeing in these settings. As background for this endeavour, we present data on the prevalence of "social smoking" and the link between drinking and smoking. Social smokers, along with those in the early phases of smoking, and former smokers who are vulnerable to relapse, are of particular concern.

\section{METHODS}

\section{Data source}

Data were from the 2002 CTS. This population based, random digit dialled household survey is conducted every three years as part of the evaluation of California's tobacco control programme. ${ }^{18}$ The 2002 CTS took place from October 2002 through January 2003. Details of the survey methods, the exact wording of the survey questionnaire items, and the survey data are available online. ${ }^{19}$ Below we provide a brief 
description of the particular features of the 2002 CTS that are most relevant to the present study.

In responding households $(45.7 \%)$, a brief interview was conducted with a household adult (18+ years) who enumerated all household residents, providing demographic information, including smoking status, for each resident. All young adults 18-29 years and a random sample of adults 30 years of age and older were selected for an approximately 25 minute extended interview on smoking behaviour, knowledge, and attitudes. A special section of the questionnaire was administered to only the young adult respondents. We report data from 9364 young adults who answered this separate section (overall, $58.6 \%$ of those enumerated on the screener instrument). A comparison of those with and without completed interviews revealed that females were more likely to cooperate than males $(63 \% \mathrm{v}$ $54 \%$ ). Cooperation rates also differed by age group (18-21: 61\%; 22-25: 56\%; 26-29: 60\%), by educational level (did not graduate from high school: $51 \%$; high school graduates: $57 \%$; some college: $61 \%$; college graduates: $63 \%$ ), and by race/ ethnicity (non-Hispanic white: 63\%; Hispanic: 54\%; African American: 56\%; Asian/Pacific Islanders: 57\%). Current smokers were somewhat less likely to cooperate (56\%) than former $(64 \%)$ or never smokers $(59 \%)$.

\section{Survey items analysed \\ Smoking status}

"Current established smokers" were defined as persons who had smoked at least 100 cigarettes in their lifetime and who now smoked every day or some days. Non-daily smokers (smoked "some days") were asked if they had ever smoked daily in the past for a period of six months or longer. Current daily smokers were asked on average how much they smoked per day and non-daily smokers were asked how many days they smoked in the last month and how many cigarettes they consumed on the days they did smoke. "Former established smokers" were defined as having smoked at least 100 cigarettes in their lifetime but presently smoked "not at all". They were asked when they quit regular smoking and when they had their last cigarette. Respondents who answered "no" to the question about having smoked at least 100 cigarettes in their lifetime, but who indicated that they had smoked a lesser number were considered "experimenters". Current experimenters were those who had had a cigarette in the past 30 days or who admitted to smoking "once in a while".

\section{Risk for future smoking}

Subgroups of non-smokers at risk for future smoking were defined. Former smokers were considered at risk if they had a cigarette in the past year. They were also considered at risk if they had not smoked in the past year but indicated that they thought about smoking and situations in which they might smoke. Experimenters were considered at risk if they were current experimenters, had a cigarette within a year of their current age (for example, if 20 years old, their last cigarette was at age 19 or 20), or did not rule out (answer "definitely not") having a cigarette in the next year. Never smokers were considered susceptible or at risk for future smoking if they did not answer "no" to a question about trying a cigarette soon or rule out smoking in the next year.

\section{Social smoking}

All current smokers and experimenters were asked to agree or disagree with the statement, "I only smoke when others are smoking". While we give the percentages of smokers agreeing with this statement for all smoking status subgroups, we subsequently define a social smoker as a "nondaily" smoker who only smokes when others are smoking.
Smoking related attitudes/behaviours

Current established smokers and experimenters were asked if they agreed or disagreed with statements about whether they generally bought their own cigarettes, smoked mostly on weekends, thought they could quit any time they wanted, were addicted to cigarettes, and that smoking was harming their health. Current established smokers and current experimenters were asked if they agreed or disagreed with a statement about whether they enjoyed smoking while drinking. All young adults were asked if they had acquired a tobacco promotional item in the past year and whether they would be willing to use one.

\section{Smoking among family and friends}

Respondents were asked three questions about smoking among family and friends: "Among close relatives, do...," "Among close friends, do...," "Among people you party with, do..., (1) all of them smoke, (2) most of them smoke, (3) most of them do not smoke, or (4) do none of them smoke?" Preliminary analyses indicated that the close relative variable did not correlate with the other two (close friends and people you party with), which were highly correlated with each other. Thus, the latter two were combined by adding the numerical responses and grouping the resulting scale as: $\leqslant 4=$ all or most; $5-6=$ most not; $\geqslant 7=$ practically none. The first two responses for the relative variable were also combined since few respondents indicated that all of their close relatives smoked.

\section{Bar or club attendance and what was observed}

All young adult respondents were asked how often they went to bars or clubs (frequently, sometimes, rarely or never). Young adults who said they attended bars or clubs at least sometimes were asked a series of questions about what they observed. They were asked if they saw people smoking inside the bars or clubs, and whether they saw people smoking just outside the entrance. They were also asked if they had seen cigarette advertisements in bars or clubs on the walls or furniture, or on napkins, coasters or giveaway items, and whether they had seen cigarettes being given away by a tobacco company representative. Finally, they were asked if they had ever attended a bar or club event sponsored by a tobacco company.

\section{Statistical methods}

So that valid population estimates could be computed, respondents were assigned weights that account for the probability of their being selected and that adjust for nonresponse. Details of the weighting procedure are available elsewhere. ${ }^{19}$ A complex survey design such as the one employed by the CTS requires special variance estimation methods that account for the fact that the sample is not a simple random sample. The CTS data were partitioned into replicate samples (each weighted separately) so that a modified jackknife procedure for variance estimation ${ }^{20}$ could be employed. This procedures is available in the SUDAAN statistical package. ${ }^{21}$ We provide $95 \%$ confidence intervals for all estimates in the text, tables, and figures. Also, statistical procedures from SUDAAN, again based on the jackknife procedure, were used to assess differences among groups $\left(\chi^{2}\right.$ tests), and examine the demographic and other factors related to bar and club attendance (multiple logistic regression).

\section{RESULTS}

In 2002, 18.4 (1.2)\% of the California young adult population were current established smokers, $9.0(0.6) \%$ were former established smokers, $6.8(0.7) \%$ were current experimenters, $22.5(0.9) \%$ were former experimenters, and $43.4(1.3) \%$ were 
Table 1 Demographic and other characteristic profile of young adult (18-29 years) social smokers compared to other non-daily smokers and daily smokers ( $n=2233$ current smokers)

\begin{tabular}{|c|c|c|c|c|}
\hline Characteristic & $n \S$ & $\begin{array}{l}\text { Social smokers } \\
\% \S(95 \% \mathrm{Cl}) \\
\mathrm{n}=525\end{array}$ & $\begin{array}{l}\text { Other non-daily } \\
\text { smokers } \\
\%(95 \% \mathrm{Cl}) \\
\mathrm{n}=682\end{array}$ & $\begin{array}{l}\text { Daily smokers } \\
\%(95 \% \mathrm{Cl}) \\
\mathrm{n}=1026\end{array}$ \\
\hline \multicolumn{5}{|l|}{ Sex } \\
\hline Female & 952 & $36.2(4.4)$ & $35.4(3.7)$ & $33.0(2.9)$ \\
\hline Male & 1281 & $63.8(4.4)$ & 64.6 (3.7) & $67.1(2.9)$ \\
\hline \multicolumn{5}{|l|}{ Age (years) } \\
\hline $18-21$ & 878 & $37.1(4.6)$ & $38.8(4.2)$ & $37.0(3.3)$ \\
\hline $22-25$ & 789 & $36.8(4.2)$ & $36.0(4.9)$ & $36.2(3.2)$ \\
\hline $26-29$ & 566 & $26.1(4.1)$ & $25.2(3.7)$ & $26.8(3.1)$ \\
\hline \multicolumn{5}{|l|}{ Race/ethnicity*** } \\
\hline Non-Hispanic white & 1164 & $34.6(3.8)$ & $37.4(3.9)$ & $52.9(3.1)$ \\
\hline Hispanic & 647 & $45.7(4.8)$ & $45.7(4.0)$ & $24.9(3.6)$ \\
\hline African American & 101 & $3.8(1.8)$ & $4.4(1.6)$ & $5.4(1.7)$ \\
\hline Asian/Pacific Islander & 216 & $11.0(3.2)$ & $9.5(3.2)$ & $11.3(2.1)$ \\
\hline Other & & & & \\
\hline \multicolumn{5}{|l|}{ Education $^{\star \star \star} \dagger$} \\
\hline No college & 1110 & $40.9(5.7)$ & $49.6(4.4)$ & $61.2(3.2)$ \\
\hline Some college, not current student & 255 & $8.0(2.9)$ & $9.1(2.1)$ & $11.9(2.4)$ \\
\hline Part time current student & 152 & $7.0(2.6)$ & $6.9(1.8)$ & $6.4(1.5)$ \\
\hline Full time current student & 389 & $22.0(4.6)$ & $17.7(3.2)$ & $11.5(2.5)$ \\
\hline College graduate & 327 & $22.1(3.9)$ & $16.8(2.8)$ & $8.9(1.8)$ \\
\hline \multicolumn{5}{|l|}{ Marital status* } \\
\hline Single & 1461 & $68.8(5.3)$ & $68.9(4.8)$ & $62.3(3.6)$ \\
\hline Partnered & 284 & $11.7(3.5)$ & $9.9(2.5)$ & $14.7(3.0)$ \\
\hline Divorced/widowed/separated & 117 & $4.8(2.2)$ & $4.0(1.7)$ & $5.2(1.5)$ \\
\hline Married & 371 & $14.7(3.5)$ & $17.3(3.5)$ & $17.7(2.9)$ \\
\hline \multirow{2}{*}{\multicolumn{5}{|c|}{ Smoking in social environment }} \\
\hline \multicolumn{4}{|l|}{ Relatives $^{* * *}$} & \\
\hline None smoke & 460 & $28.4(5.2)$ & $24.0(3.3)$ & $15.9(2.7)$ \\
\hline Most do not smoke & 1149 & $51.5(5.7)$ & $57.6(4.6)$ & $44.3(3.7)$ \\
\hline Most or all smoke & 624 & $20.2(3.9)$ & $18.4(3.4)$ & $39.9(3.5)$ \\
\hline \multicolumn{5}{|l|}{ Friends ${ }^{* * *}$} \\
\hline Practically none smoke & 126 & $7.1(2.5)$ & $11.1(9.3)$ & $2.1(5.6)$ \\
\hline Most do not smoke & 1069 & $55.1(5.0)$ & $53.9(2.8)$ & $39.8(3.2)$ \\
\hline Most or all smoke & 1038 & $37.8(5.3)$ & $35.1(3.1)$ & $58.0(3.5)$ \\
\hline \multicolumn{5}{|l|}{ Smoking behaviour, attitudes } \\
\hline Cigarettes/month (mean) $)^{* * *}+1 \dagger$ & 2233 & $23.3(5.0)$ & $55.1(8.6)$ & $387.5(18.3)$ \\
\hline Statusttt & 1207 & & & \\
\hline Experimenter & 569 & $55.6(4.2)$ & $40.3(5.4)$ & \\
\hline Never daily & 335 & $26.6(4.1)$ & $32.0(4.9)$ & \\
\hline Once daily & 303 & $17.8(3.1)$ & $27.8(4.3)$ & \\
\hline Never a regular smokert†† & 1207 & $47.0(4.0)$ & $30.6(4.3)$ & \\
\hline Buys own cigarettes** $+\dagger \dagger$ & 2233 & $26.0(4.2)$ & $62.0(4.9)$ & $94.6(1.8)$ \\
\hline Smokes mostly on weekends ${ }^{* * *}+† \dagger$ & 2233 & $53.2(4.7)$ & $30.4(4.8)$ & $4.9(1.4)$ \\
\hline Could quit anytime I wanted ${ }^{* * *}+\dagger \dagger$ & 2233 & $84.7(3.7)$ & $71.5(3.8)$ & $40.3(3.8)$ \\
\hline Am addicted to cigarettes ${ }^{* * *}+1 \dagger$ & 2233 & $10.0(2.6)$ & $20.5(3.8)$ & $77.8(4.0)$ \\
\hline Smoking harming my health*** & 2233 & $41.2(4.0)$ & $54.7(5.3)$ & $96.1(1.3)$ \\
\hline $\begin{array}{l}\text { §Unweighted sample size and weigh } \\
{ }^{* \star *} p<0.001,{ }^{*} p<0.05 \text { for } \chi^{2} \text { compa } \\
\dagger+t p<0.001,+p<0.05 \text { for } \chi^{2} \text { comp } \\
C l \text { confidence interval. }\end{array}$ & ercent & $\begin{array}{l}\text { ges. } \\
\text { groups. } \\
\text { cial versus }\end{array}$ & -daily smokers. & \\
\hline
\end{tabular}

never smokers. Of former established smokers, $59.6(4.3) \%$ were at risk of smoking again. Altogether, over half of experimenters $(52.2(2.0) \%)$ were at risk to smoke in the future. However, only 9.0 (1.2)\% of never smokers were still at risk of smoking in the future. Current established smokers and experimenters, together with the groups of non-smokers at risk for future smoking, accounted for 43.0 (1.2)\% of the young adult population 18 to 29 years of age in California.

Before examining who goes to bars and clubs and what is observed in these settings, we provide some background material regarding young adults who say that they smoke only when others are smoking, and the link between smoking and drinking.

\section{Social smoking}

In all, $30.0(2.2) \%$ of all current smokers and experimenters agreed with the statement that they only smoked when others were smoking. As expected, limiting smoking to social settings was related to smoking level. However, a meaningful percentage of moderate to heavy daily smokers (15+ cigarettes/day), 8.9 (3.2)\%, said they only smoked when others did. This percentage increased to 17.6 (4.4)\% for light daily smokers ( $<15$ cigarettes/day), to 34.8 (6.0)\% for once daily non-daily smokers, to $40.2(6.2) \%$ for never daily nondaily smokers and to 52.0 (4.9)\% for current experimenters.

In table 1 , we restrict the definition of a social smoker to current non-daily smokers (including experimenters) who only smoke when others are smoking, and we compare this group to other non-daily smokers with respect to their demographic profile, smoking behaviour, and attitudes. Data for daily smokers are also presented as a point of reference. There was little difference between social smokers and other non-daily smokers regarding sex, age, race/ethnicity, marital status, or the presence of smokers in their social environment. However, relatively more social smokers were full time college students or college graduates. The profiles of daily 


\begin{tabular}{|c|c|c|c|}
\hline Characteristics & $n \S$ & $\begin{array}{l}\text { Go to bars and clubs } \\
\text { at least sometimes } \\
\% \S( \pm 95 \% \mathrm{Cl})\end{array}$ & $\begin{array}{l}\text { Adjustedt } \\
\text { Odds ratio } 195 \% \mathrm{Cl}\end{array}$ \\
\hline Overall & 9364 & $33.8(1.2)$ & \\
\hline \multicolumn{4}{|l|}{ Sex } \\
\hline Female & 5002 & $28.3(1.6)$ & 1.00 \\
\hline Male & 4362 & $38.7(1.9)$ & 1.18 (1.03 to 1.35$)$ \\
\hline \multicolumn{4}{|l|}{ Age (years) } \\
\hline $18-21$ & 3725 & $28.7(1.8)$ & 1.00 \\
\hline $22-25$ & 2885 & $42.3(2.4)$ & 1.99 (1.69 to 2.35$)$ \\
\hline $26-29$ & 2754 & $31.6(2.1)$ & 1.65 (1.36 to 2.02 ) \\
\hline \multicolumn{4}{|l|}{ Race/ethnicity } \\
\hline Non-Hispanic white & 4212 & $38.7(2.1)$ & 1.00 \\
\hline Hispanic & 3245 & $29.0(1.7)$ & 0.99 (0.87 to 1.14$)$ \\
\hline African American & 495 & $35.2(4.6)$ & 1.18 (0.91 to 1.53$)$ \\
\hline Asian/Pacific Islander & 1085 & $34.6(3.7)$ & 0.80 (0.66 to 0.98 ) \\
\hline Other & 324 & $33.3(7.2)$ & 0.96 (0.66 to 1.41$)$ \\
\hline \multicolumn{4}{|l|}{ Education } \\
\hline No college & 4162 & $25.7(1.6)$ & 1.00 \\
\hline Some college, not current student & 992 & $36.2(3.8)$ & 1.57 (1.29 to 1.91$)$ \\
\hline Part time current student & 611 & $41.9(4.6)$ & 1.89 (1.51 to 2.36$)$ \\
\hline Full time current student & 1823 & $38.9(2.5)$ & 1.81 (1.53 to 2.13$)$ \\
\hline College graduate & 1776 & $46.2(2.6)$ & 2.53 (2.08 to 3.08 ) \\
\hline \multicolumn{4}{|l|}{ Marital status } \\
\hline Single & 5727 & $40.7(1.6)$ & 1.00 \\
\hline Divorced/widowed/separated & 314 & $36.1(6.1)$ & $0.73(0.54$ to 1.00$)$ \\
\hline Partnered & 958 & $28.9(2.9)$ & 0.52 (0.44 to 0.62 ) \\
\hline Married & 2365 & $18.8(1.7)$ & 0.33 (0.28 to 0.38 ) \\
\hline \multicolumn{4}{|l|}{ Smoking in social environment } \\
\hline \multicolumn{4}{|l|}{ Relatives } \\
\hline None smoke & 2887 & $28.9(2.0)$ & 1.00 \\
\hline Most do not smoke & 4734 & $37.5(1.7)$ & $1.30(1.16$ to 1.45$)$ \\
\hline Most or all smoke & 1743 & $32.4(2.3)$ & 1.05 (0.88 to 1.24$)$ \\
\hline \multicolumn{4}{|l|}{ Friends } \\
\hline Practically none smoke & 2733 & $21.3(1.9)$ & 1.00 \\
\hline Most do not smoke & 4551 & $37.2(1.9)$ & $1.48(1.25$ to 1.75$)$ \\
\hline Most or all smoke & 2080 & $42.2(2.5)$ & 1.57 (1.28 to 1.92$)$ \\
\hline \multicolumn{4}{|l|}{ Smoking status } \\
\hline Never, not susceptible & 3743 & $21.2(2.0)$ & 1.0 \\
\hline Never, susceptible & 326 & 29.6 (7.3) & $1.75(1.18$ to 2.59$)$ \\
\hline Experimenter, not susceptible & 1349 & $30.9(2.1)$ & $1.47(1.23$ to 1.76$)$ \\
\hline Experimenter, susceptible & 822 & $44.4(4.8)$ & $2.64(2.04$ to 3.41$)$ \\
\hline Former, not vulnerable & 362 & $27.6(4.6)$ & $1.45(1.11$ to 1.90$)$ \\
\hline Former, vulnerable to relapse & 528 & $42.1(5.4)$ & 2.26 (1.73 to 2.97$)$ \\
\hline Social only & 525 & $55.6(5.2)$ & 3.14 (2.41 to 4.08$)$ \\
\hline Other non-daily & 682 & $50.4(5.3)$ & 2.97 (2.26 to 3.88 ) \\
\hline Daily & 1026 & $50.3(3.9)$ & 3.46 (2.63 to 4.55$)$ \\
\hline \multicolumn{4}{|l|}{ Receptivity to tobacco promotions } \\
\hline No & 7353 & $30.3(2.0)$ & 1.0 \\
\hline Yes & 2011 & $46.4(2.5)$ & $1.33(1.15$ to 1.55$)$ \\
\hline
\end{tabular}

smokers were different than the non-daily smokers for most variables.

Social smokers only smoked on average about 23 cigarettes/month, less than one a day, whereas other non-daily smokers averaged 55 cigarettes/month (about 1.8 cigarettes/ day). Compared to other non-daily smokers, social smokers were more likely to be experimenters and to have never smoked regularly or on a daily basis. They were also less likely to buy their own cigarettes, more likely to smoke only on weekends, more likely to think that they could quit anytime they wanted, and less likely to think that they were addicted to cigarettes or that cigarettes were harming their health.

\section{Smoking and drinking}

Nearly three quarters (74.5 (2.3)\%) of all young adult current smokers (established and experimenters) said they enjoyed smoking while drinking. Daily smokers $(86.8(2.5) \%)$ were more likely than social smokers $(69.1(4.1) \%)$ or other nondaily smokers $(61.1(4.9) \%)$ to indicate this combination.

\section{Bar and club attendance}

About one third (33.8 (1.2)\%) of all young adults indicated that they go to bars and clubs at least sometimes. Table 2 shows the percentages of different subgroups of the young adult population that go to bars and clubs at least sometimes (attenders) and the comparative likelihood of attending derived from a multivariate analysis adjusting for all other variables in the table. Males were more likely than females to go to bars and clubs. Those in the two older age groups (compared to the youngest group) and those with some college experience (compared to those with none) were also more likely to be bar and club attenders. Asian/Pacific Islanders were less likely than non-Hispanic whites to attend bars and clubs. Married or partnered individuals appeared less likely to go to bars or clubs than never married (single) individuals, and even the formerly married were marginally less likely than single individuals to be bar or club attenders.

Young adults with a few relatives but not most or all who smoke were more likely to attend bars and clubs compared to those with no close relatives who smoke. The association of 


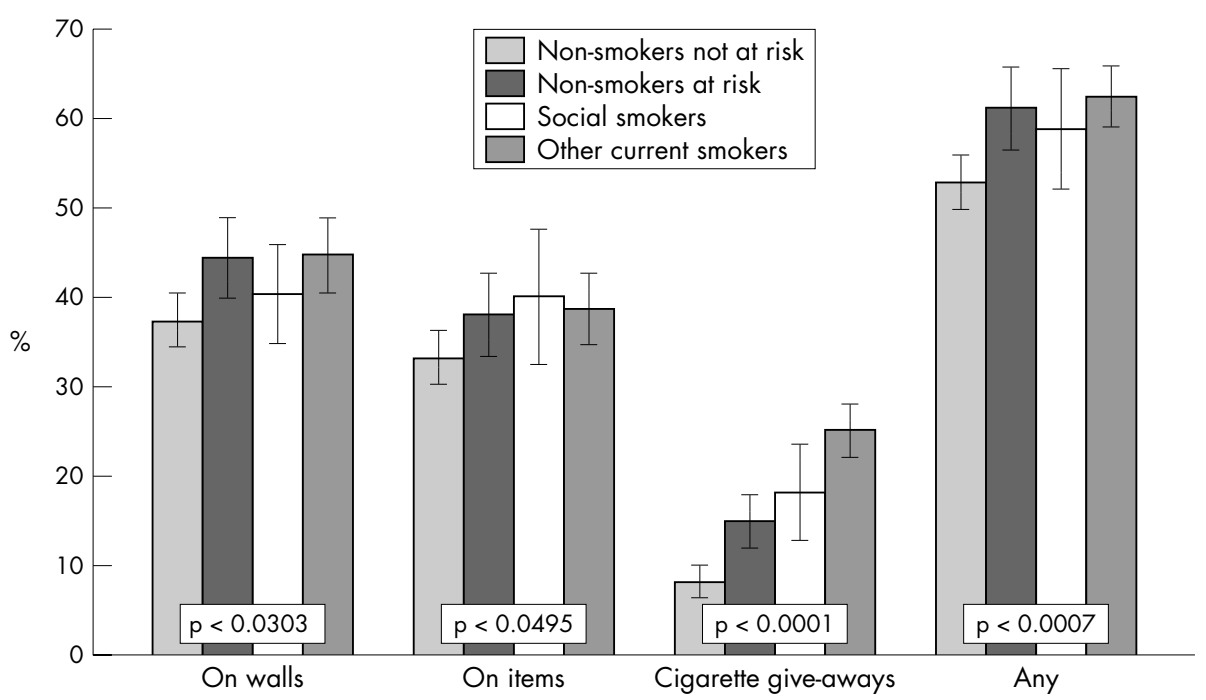

Figure 1 Percentage of young adults who recalled seeing cigarette advertising and promotions in bars and clubs according to whether or not they were non-smokers not at risk, nonsmokers at risk for future smoking, social smokers, or other current smokers.

bar and club attendance with friends who smoke was stronger; those reporting that most or all of their friends smoke were most likely to go to bars and clubs. Yet, even those who reported that practically none of their friends smoked were more likely to attend compared to those with no friends who smoked.

Bar and club attendance was highly related to smoking status, even after adjustment for the other variables in the model, including the social influences of family and friends' smoking. Never smokers susceptible to smoking were more likely to attend bars and clubs than those committed not to smoke. Experimenters were also more likely to be attenders than committed never smokers, with those susceptible to smoking significantly more likely than those not susceptible to attend bars and clubs. Again, former smokers were more likely to be bar and club attenders than the committed never smokers, and while former smokers vulnerable to relapse appeared somewhat more likely to be attenders, the confidence intervals for these two odds ratios were overlapping. All current smokers showed high rates of bar or club attendance, with social smokers over three times more likely than committed never smokers to go to bars and clubs at least sometimes.

Having or being willing to use a tobacco promotional item was also independently related to bar and club attendance, increasing the odds of bar or club attendance by $37 \%$. Further analyses revealed that current smokers were much more likely than other young adults to have or be willing to use tobacco promotional items $(39.7(2.6) \%$ v $16.0 \quad(1.0) \%$, respectively, $\mathrm{p}<0.001)$. Just considering non-smokers, bar and club attenders were more receptive to tobacco promotions $(23.3(2.4) \%)$ than those who rarely or never went to bars or clubs (13.2 (0.8)\%), p < 0.001). Finally, non-smokers at risk for future smoking were more likely to be receptive (24.1 $(2.0) \%)$ than non-smokers not at risk for future smoking (13.5 (1.0)\%) p $<0.001)$.

What was observed in bars and clubs

Of those who attended bars and clubs at least sometimes, $41.7(2.1) \%$ reported seeing cigarette advertisements on the walls or furniture, $36.5(2.0) \%$ reported seeing them on napkins, coasters or giveaway items, and 15.4 (1.6)\% saw tobacco company representatives handing out free cigarette samples. Overall, 57.9 (2.2)\% of bar and club attenders reported observing at least one of these advertising and promotional practices.
Figure 1 reports the percentages seeing the various advertising and promotions in bars clubs according to whether the respondent was a non-smoker not at risk for future smoking, a non-smoker at risk, a social smoker, or another current smoker. Compared to non-smokers not at risk, non-smokers at risk and smokers showed higher reported rates of seeing advertising on walls or furniture or on items such as napkins and coasters. As might be expected, current smokers (other than social smokers) were much more likely than the other groups to have reported seeing cigarettes being given away by tobacco company representatives, although social smokers appeared to be more aware of these promotions as well.

Just over $10 \%(11.3(1.3) \%)$ of young adults reported that they had attended a bar or club event sponsored by a tobacco company. Overall, 96.9 (0.7)\% of bar and club attenders reported seeing people smoke just outside the entrance, and despite California's total ban on smoking in these indoor workplace venues since January 1998, nearly half (49.1 $(1.9) \%)$ reported seeing someone smoking inside a bar or club.

\section{DISCUSSION}

This study confirms the importance of bars and clubs for the tobacco industry in gaining access to young people with their advertising and promotions. Since about three quarters of young adult smokers reported that they enjoyed smoking while drinking, the link between drinking and smoking is well established. In California, about one third of all young adults attend bars and clubs at least sometimes, and nearly $60 \%$ of bar and club goers said they saw tobacco advertising and promotions in these settings; this translates to about $20 \%$ (60\% of one third) of the total young adult population $18-29$ years of age. Among young adults at risk for future smoking, who more often reported going to bars and clubs and more often reported seeing advertising and promotions there, the tobacco industry has gained access to about 30\% (60\% of one half).

Joining in and enjoying the activities of drinking and smoking in the social settings that bars and clubs provide may be responsible in part for the creation of "social smokers". For this group, a further industry goal would be to escalate their smoking toward dependence. Social smokers tended not to think of themselves as addicted and thought they could quit whenever they wanted. Whether these social smokers will become dependent smokers cannot be 
determined from our cross sectional survey. Results from a recent longitudinal study of college freshmen and sophomores suggested that only about $10 \%$ of occasional smokers progressed to daily smoking, and about half quit during a four year follow up period..$^{22}$ Many of these occasional smokers may have been mainly social smokers. Thus, it is possible that a substantial proportion of social smokers may be able to keep from becoming dependent on nicotine in the future, but the risk for some remains. Bars and clubs may also be a setting in which former established smokers are likely to relapse.

Social smoking among young adults has only been studied relatively recently ${ }^{23-25}$; in previous studies, the definition was less strict than in our analysis. Social smokers have generally been defined as those who "smoke more when they are with other smokers than when alone" or "who mostly smoke when around other smokers". We asked smokers to agree with the statement, "I only smoke when others are smoking". About $30 \%$ of current smokers (including experimenters) agreed with this statement, which is about the same as in a Massachusetts population study of 18-30 year olds, ${ }^{25}$ but less than a study of college students indicating that $51 \%$ were social smokers. ${ }^{24}$ Our study suggests that social smoking may be more prevalent among college students.

In 1998, California was the first US state that prohibited smoking in bars and clubs as indoor workplaces. Smoke-free workplaces not only protect non-smokers from secondhand smoke, but also tend to inhibit smoking behaviour. ${ }^{26-29}$ It would be expected that smoke-free bars would help to decouple drinking and smoking. Research in Australia suggested that smoke-free policies might help eliminate socially cued smoking in bars and clubs. ${ }^{30-31}$ Our data indicate that in 2002, despite the smoke-free law, nearly half of young adults who patronise bars and clubs had seen people smoking inside, although some of these instances may have occurred only very rarely or before California bars and clubs became smoke-free. The high rate of seeing smoking in bars and clubs may also be partly due to many California bars and clubs having outdoor patron patios where smoking is allowed. In any case, smokers can step outside to smoke.

Thus, smoke-free policies may not be as effective as anticipated in decoupling smoking and drinking. Further, it is likely that smokers tend to patronise more "smoker friendly" establishments that may be less likely to enforce the law prohibiting smoking indoors and more likely to have cigarette advertising and promotions, including cigarette giveaways on the premises. A study conducted before bars and clubs were smoke-free in the Boston area reported that those featured in cigarette advertising in a widely available entertainment weekly publication showed important differences compared to those not featured; perceived smoking prevalence and the percentage of patrons under 25 years of age appeared higher in the establishments featured, suggesting that they were indeed both more youth and smoker friendly. ${ }^{32}$

Our results indicate that smokers, former smokers vulnerable to relapse, and experimenters and never smokers susceptible to smoking were more likely to be bar and club attenders than never smokers committed not to smoke. This association was strong and held even after adjustment for demographics and the presence of smokers in the social environment. Further, having or being willing to use a tobacco promotional item was also related to bar and club attendance. However, bars and clubs may be an important setting for young adults to obtain such items, since the 1998 Master Settlement Agreement banned distribution in other than adults only venues. ${ }^{10}$ Thus, the direction of the association between having or being willing to use a tobacco promotional item and bar and club attendance is not clear.
What this paper ads

Tobacco industry documents clearly indicate that cigarette companies target young adults with advertising and promotions in bars and clubs. However, it is not known what fraction of the young adult population might be exposed to and potentially influenced by these efforts.

The results of this study indicate that about $20 \%$ of the California young adult (18-29 years) population attends bars and clubs and has seen cigarette advertising and promotions in these venues and might be influenced. The percentage is even higher $(\sim 30 \%)$ for those at risk for future smoking. Because of study limitations, these results are likely conservative.

Bar and club attendance appears lower in California than in Massachusetts. The Massachusetts population study indicated that $44 \%$ of young adults aged $18-30$ years went to a bar or club at least weekly. ${ }^{25}$ Our definition was less precise, but "at least sometimes" should have captured more people than "at least weekly", yet only about one third indicated attending at least sometimes. Whether bar and club attendance by young adults in other states is more similar to that observed in California or in Massachusetts is unknown.

A strength of our study is that it addresses the problem of cigarette advertising and promotions in the general population of young adults, rather than being limited to college students, a population much more often studied, ${ }^{33-36}$ and with lower smoking rates than those who never attended college..$^{35}$ 36-39 However, as a cross sectional survey, it has several limitations. We examined reported exposure and receptivity, but we cannot relate these to future smoking behaviour. Although receptivity to tobacco advertising and promotions has been related to future smoking among adolescents, ${ }^{4-6}$ we can only hypothesise that it might have a similar role for young adults. The variables used to define risk among never smokers and experimenters in our study have been highly predictive in longitudinal studies of adolescents, ${ }^{40-43}$ but again, such studies are needed in young adults. The type of variables used to define risk among former established smokers should be associated with increased relapse risk, ${ }^{44}$ but the young adult group has not specifically been studied. Since our data are from self report, there may be some inaccuracies in our categorisations, but self report data has generally been found to be sufficiently accurate for smoking status both in adults ${ }^{45}$ and adolescents ${ }^{46}$ for most research purposes.

The generalisability of these results to all young adult Californians is limited by the response rates to these types of surveys. Young adults are particularly difficult to reach in telephone surveys that do not sample cell phones, despite repeated callbacks at all times of the day and week, because they are often not at home. Smokers and some groups with relatively high smoking rates (for example, males, those with less education) were less likely to have completed the extended interview. Smokers in particular showed high rates of bar and club attendance. Thus, if more young adults who are habitually not at home had been included in our sample, it is possible that an even higher percentage of the young adult population would have been identified as bar and club attenders, and thus likely to be exposed to bar and club advertising and promotions.

Accordingly, we believe that our estimate from California data that $20 \%$ of the young adult population 18-29 years of age has been accessed by the tobacco industry through its advertising in bars and clubs may be conservative for Californians and probably for the rest of the USA. 
Nevertheless, the estimated $20 \%$ of young adult Californians (about 285000 individuals in this age group) who were potentially influenced by the advertising and promotions they saw in bars and clubs is sizable. It is, therefore, essential that effective tobacco control counter measures aimed at young adults be explored and implemented. ${ }^{7647}$

\section{ACKNOWLEDGEMENTS}

This work was supported by the Tobacco Related Disease Research Program grant 12RT-0082 from the University of California. Data for the California Tobacco Surveys were collected under contract 0116370 (2002) from the California Department of Health Services, Tobacco Control Section, Sacramento, California. Victoria White's work on this article was conducted while she was a UICC YamagiwaYoshida Memorial Study Grant fellow at Cancer Prevention and Control, University of California, San Diego.

\section{Authors' affiliations}

E A Gilpin, J P Pierce, Cancer Prevention and Control Program, Cancer Center, University of California, San Diego, La Jolla, California, USA V M White, Centre for Behavioural Research in Cancer, The Cancer Council Victoria, Carlton Victoria, Australia

Competing interests: none declared

\section{REFERENCES}

1 Difranza JR, Richards JW, Paulman PM, et al. RJR Nabisco's cartoon camel promotes camel cigarettes to children. JAMA 1991;266:3149-53.

2 Fischer PM, Schwartz MP, Richards JW, et al. Brand logo recognition by children aged 3 to 6 years. Mickey Mouse and Old Joe the Camel. JAMA 1991;266:3145-8.

3 Pierce JP, Gilpin EA, Burns DM, et al. Does tobacco advertising target young people to start smoking? Evidence from California. JAMA 1991;266:3154-8.

4 Pierce JP, Choi WS, Gilpin EA, et al. Tobacco industry promotion of cigarettes and adolescent smoking. JAMA 1998;279:511-15.

5 Biener L, Siegel M. Tobacco marketing and adolescent smoking: more support for a causal inference. Am J Public Health 2000;90:407-1 1 .

6 Sargent JD, Dalton $M$, Beach $M$, et al. Effect of cigarette promotions on smoking uptake among adolescents. Prev Med 2000;30:320-7.

7 Ling PM, Glantz SA. Why and how the tobacco industry sells cigarettes to young adults: evidence from industry documents. Am J Public Health 2002;92:908-16

8 Katz SK, Lavack AM. Tobacco related bar promotions: insights from tobacco industry documents. Tobacco Control 2002;11(suppl I):i92-101.

9 Rigotti NA, Moran SE, Wechsler H. US college students' exposure to tobacco promotions: prevalence and association with tobacco use. Am J Public Health 2005;95: 138-44.

10 National Association of Attorneys General. Tobacco Settlement Summary; 1998. http://www.naag.org/glance.htm.

11 Sepe E, Glantz SA. Bar and club tobacco promotions in the alternative press: targeting young adults. Am J PublicHealth 2002;92:75-8

12 MacDonald TK, Zanna MP, Fong GT. Decision making in altered states: effects of alcohol on attitudes toward drinking and driving. J Pers Soc Psychol 1995;68:973-85

13 Gray NL. The relationship of cigarette smoking and other substance use among college students. J Drug Educ 1993;23:117-24.

14 Schoring JB, Gutgesell M, Klas P, et al. Tobacco, alcohol and other drug use among college students. J Subst Abuse 1994:6:105-15.

15 Bell R, Wechsler H, Johnston LD. Correlates of college student marijuana use: results of a US national survey. Addiction 1997;92:571-81.

16 McKee SA, Hinson R, Rounsaville D, ef al. Survey of subjective effects of smoking while drinking among college students. Nicotine Tob Res 2004;6:111-17.

17 Rose JE, Braver LH, Behm FM, et al. Psychopharmacological interactions between nicotine and ethanol. Nicotine Tob Res 2004;6:133-44

18 Bal DG, Kizer KW, Felten PG, et al. Reducing tobacco consumption in California. JAMA 1990;264:1570-4.

19 University of California San Diego, Social Science Data Collection (UCSD SSDC); 2004. Final Reports, Survey Data, and Technical Documentation for the California Tobacco Surveys. http://ssdc.ucsd.edu/tobacco.
20 Effron B. The jackknife, the bootstrap and other resampling plans: CMBS Regional Conference Series in Applied Mathematics 38. Philadelphia: Society for Industrial and Applied Mathematics, 1982.

21 Research Triangle Institute. SUDAAN. Version 8.0. Research Triangle Park, North Carolina: Research Triangle Institute, 2002.

22 Wetter DW, Kenford SL, Welsch SK, et al. Prevalence and predictors of transitions in smoking behavior among college students. Health Psychol 2004;23:168-77.

23 Rollins S, Schumacher JRM, Ling P. Exploring the phenomenon of social smoking - Why do so many young adults socially smoke: Abstract MEDI-161. Presented at the 2002 National Conference on Tobacco or Health, San Francisco, November 19-21, 2002.

24 Moran S, Rigotti NA, Wechsler H. Social smoking by U.S. College Students. Abstract PA9-7. Presented at the Society for Research on Nicotine and Tobacco, New Orleans, February 19-22, 2003.

25 Biener $L$, Albers AB. Young adults: vulnerable new targets of tobacco marketing. Am J Public Health 2004;94:326-30.

26 Farkas AJ, Gilpin EA, Distefan JM, et al. The effects of household and workplace smoking restrictions on quitting behaviors. Tobacco Control 1999:8:261-5.

27 Chapman S, Borland R, Scollo M, et al. The impact of smoke-free workplaces on declining cigarette consumption in Australia and the United States. Am J Public Health 1999;89:1018-23.

28 Farelly MC, Evans WN, Sfekas AES. The impact of workplace smoking bans: results from a national survey. Tobacco Control 1999;8:272-7.

29 Heloma A, Jaakkola MS, Kahkonen E, et al. The short-term impact of national smoke-free workplace legislation on passive smoking and tobacco use. Am J Public Health 2001;91:1416-18.

30 Trotter L, Wakefield M, Borland R. Socially cued smoking in bars, nightclubs, and gaming venues: a case for introducing smoke-free policies. Tobacco Control 2002;11:300-4.

31 Philpot SJ, Ryan SA, Torre LE, et al. Effect of smoke-free policies on the behavior of social smokers. Tobacco Control 1999;8:278-81.

32 Biener L, Nyuman AL, Kline RL, et al. Adults-only: the prevalence of tobacco promotions in bars and clubs in the Boston area. Tobacco Control 2004; 13:403-8.

33 Emmons KM, Wechsler H, Dowdall G, et al. Predictors of smoking among US college students. Am J Public Health 1998;88:9-11.

34 Everett SA, Husten CG, Kann L, et al. Smoking initiation and smoking patterns among US college students. J Am Coll Health 1999;48:55-60.

35 Lantz PM. Smoking on the rise among young adults: implications for research and policy. Tobacco Control 2003; 12(suppl I):i60-70.

36 Gilpin EA, White M, White V, et al. Tobacco control successes in California: a focus on young people. Results from the California Tobacco Surveys, 1990-2002. La Jolla, California: University of California, San Diego, 2003.

37 Moskal PD, Dziuban CD, West GB. Examining the use of tobacco on college campuses. J Am Coll Health 1999:47:260-5.

38 Rigotti NA, Lee JE, Wechsler H. US college students' use of tobacco products: results of a national survey. JAMA 2000;284:699-705.

39 Escobedo LG, Peddicord JP. Smoking prevalence in US birth cohorts: the influence of gender and education. Am J Public Health 1996;86:231-6.

40 Pierce JP, Choi WS, Gilpin EA, et al. Validation of susceptibility as a predictor of which adolescents take up smoking in the US. Health Psychol 1996:15:355-61.

41 Unger JB, Johnson CA, Stoddard JL, et al. Identification of adolescents at risk for smoking initiation: validation of a measure of susceptibility. Addict Behav 1997;22:81-91.

42 Choi WS, Gilpin EA, Farkas AJ, et al. Determining the probability of future smoking among adolescents. Addiction 2001;96:313-23.

43 Jackson C. Cognitive susceptibility to smoking and initiation of smoking during childhood; a longitudinal study. Prev Med 1998;27:129-34.

44 Mclntyre KO, Lichtenstein E, Mermelstein RJ. Self-efficacy and relapse in smoking cessation: A replication and extension. J Consul Clin Psychol 1983;51:632-3.

45 Hatziandreu EJ, Pierce JP, Fiore MC, et al. The reliability of self-reported cigarette consumption in the United States. Am J Public Health 1989;79:1020-3.

46 Caraballo RS, Giovino GA, Pechacek TF. Self-reported cigarette smoking versus serum cotinine among U.S. adolescents. Nicotine Tob Res 2004:6:19-25.

47 Backinger CL, Fagan $\mathrm{P}$, Matthews $\mathrm{E}$, et al. Adolescent and young adult tobacco prevention and cessaton: current status and future directions. Tobacco Control 2003; 12(suppl IV):iv46-53. 